\title{
The Influence of Text Message Reminders on Oral Hygiene Compliance in Orthodontic Patients
}

\author{
Asem A. M. Abdaljawwad \\ B.D.S., M.Sc. - Assistant Lecturer, Department of Orthodontics, College of Dentistry, Al-Anbar University.
}

\begin{abstract}
Objective: To determine if text message reminders regarding oral hygiene have an effect on maintaining good oral hygiene in orthodontic patients.

Materials and Methods: In this randomized, controlled clinical trial, 34 orthodontic patients were assigned to a text message or control group. Patients in the text message group received 2 reminder text messages each week for 4 weeks and one reminder text message for 8 weeks thereafter. Oral hygiene compliance was measured using bleeding index (BI), modified gingival index (MGI), and plaque index (PI) at baseline (T0), at 4 weeks after baseline (T1), and at 8 weeks after baseline (T2).

Results: Text message group had highly significant lower $\mathrm{BI}, \mathrm{MGI}$, and PI scores than control group at $\mathrm{T} 2$.

Conclusion: The use of text message reminders sent by the orthodontist was effective for improving oral hygiene compliance in orthodontic patients.
\end{abstract}

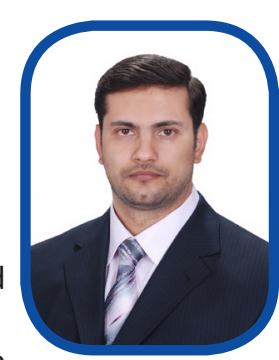

KEY WORDS

Oral hygiene; Text message; Orthodontics; Compliance.

CITE THIS ARTCLE

Abdaljawwad A. The Influence of Text Message Reminders on Oral Hygiene Compliance in Orthodontic Patients. Iraqi Dent. J. 2016; 38(1):58-62. http://www.iraqidentaljournal.com

\section{INTRODUCTION}

Oral hygiene compliance is one of the most important factors controlled by the patient during orthodontic treatment. Gingival inflammation can lead to detrimental effects to the periodontium, including recession, pocket formation, hyperplasia, and subsequent periodontal disease. ${ }^{(1-9)}$ Previous studies have shown a rapid decline in oral hygiene after the initial bonding, followed by an improvement by the fifth month of treatment. ${ }^{(10)}$ However, other studies have also demonstrated that oral hygiene problems are highest at the end of orthodontic treatment, demonstrating the challenge in obtaining sustained and acceptable oral hygiene during orthodontic therapy.(11) Effective plaque removal and oral hygiene compliance have been important concerns for orthodontists. It is well known that oral hygiene compliance can be challenging with the orthodontic treatment population. ${ }^{(12-16)}$ These undesired side effects can lead to unsatisfactory results of orthodontic therapy. ${ }^{(1)}$

In medicine and dentistry, Studies have shown text messaging to be an effective tool for behavioral change and disease prevention. ${ }^{(17,18)}$ A 2009 systematic review of the influence of text messages on behavior changes in the medical field demonstrated positive behavior changes in 13 of the 14 studies that met the authors' inclusion criteria, including smoking cessation therapy, diabetes self-management, and anti-obesity behavior. ${ }^{(19)}$ In dentistry, text message reminders, postal, and automated telephone were effective in reducing appointment no-show rates. $(20,21,22,23)$ Additionally, follow-up text message sent from an orthodontic office following initial appliance placement resulted in patient's lower levels of selfreported pain. (24) Another study showed that text message reminders to parents of orthodontic patients were shown to be an effective way to improve oral hygiene in these patients. ${ }^{(25)}$ With the introduction of text messaging, it has become easier to communicate with the patient.

The aim of this study was to determine the effectiveness of reminding patients of maintaining good oral hygiene via text message reminders sent to them weekly encouraging them about oral hygiene compliance.

\section{MATERIALS AND METHODS}

This randomized controlled clinical trial was conducted on a convenience sample of 34 consecutively orthodontic patients. Subjects were required to be in active treatment with full fixed appliances in both arches, between the ages of 17 and 23 , without any significant medical/dental history, have worn the appliance for at least 2 months and have at least 6 months of remaining orthodontic treatment and own a cellular telephone with text messaging services.

The text message group was composed of 10 girls and 7 boys, while the control group included 11 girls and 6 boys. The text message group receives two standardized text messages each week for the duration 
of the study, while the control group did not receive any text messages. Subjects were blinded as to group status and were not made aware that text messages were part of the study.

At the start of treatment, all patients were given standardized oral hygiene instruction and checked to have an oral hygiene kit that included a toothbrush, interproximal brush, and mouthwash, and was given an oral hygiene instruction sheet. At time point (T0), baseline readings of the Ramfjord teeth (maxillary right first molar, maxillary left central incisor, maxillary left first premolar, mandibular left first molar, mandibular right central incisor, and mandibular right first premolar) were recorded for bleeding index (BI), modified gingival index (MGI), and plaque index (PI). Probing was done by the same examiner for all subjects to standardize periodontal probing, and cheek retractors were placed to properly measure BI.

The BI was scored as described by Saxton and van der Ouderaa ${ }^{(26)}$ upon probing the mesio-buccal, direct buccal and disto-buccal aspects of the gingival sulci of the Ramfjord teeth. BI scoring is described in Table 1. ${ }^{(26)}$ The MGI measurement of the buccal marginal gingiva for each Ramfjord tooth was scored as described in Table 2. The PI measurement was recorded for the buccal surface of each Ramfjord tooth according to the Turesky modification on the Quigley-Hein PI scoring system and is described in Table $3^{\text {(27) }}$.

The text message group received messages twice a week for 4 weeks (totaling 8 texts) as a reminder and encouragement to practice good oral hygiene. The standardized text message was: "Remember, your smile is the first thing people see, cleaning them after every meal for at least 2 minutes will keep them beautiful, healthy and bleeding free. See you soon". The control group received no text messages. After the 4 weeks period, both groups were reevaluated. Following the first time point (T1), the text group received a text once a week for 8 weeks. After this second time period (T2), both groups were reevaluated again. Mean BI, MGI, and PI scores were compared between groups across three time points using paired samples t-test, within group scores were compared using one way analysis of variance (ANOVA). The significance level was set at $P<.5$ (significant) and $P<.001$ (highly significant). SPSS 22 software under windows 10 was used for all statistical analysis.

Table 1: Bleeding Index (BI) Measurements:

\begin{tabular}{c|c} 
score & presentation \\
\hline 0 & Absence of bleeding after 30 seconds \\
\hline 1 & Bleeding observed after 30 seconds \\
\hline 2 & Immediate bleeding \\
\hline
\end{tabular}

Table 2: Modified Gingival Index (MGI) Measurements:

\begin{tabular}{c|c|}
\hline score & presentation \\
\hline 0 & Absence of inflammation \\
\hline 1 & Mild inflammation (marginal or papillary unit) \\
\hline 2 & Mild inflammation (entire marginal and papil- \\
\hline 3 & lary unit) \\
\hline 4 & Moderate inflammation \\
\hline
\end{tabular}

Table 3: Plaque Index (PI) Measurements:

\begin{tabular}{|c|c|}
\hline Score & presentation \\
\hline 0 & No plaque \\
\hline 1 & Discontinuous band of plaque at gingival margin \\
\hline 2 & Up to $1-\mathrm{mm}$ continuous band of plaque at gingival margin \\
\hline 3 & Band of plaque wider than $1 \mathrm{~mm}$ but less than $1 / 3$ of surface \\
\hline 4 & Plaque covering between $1 / 3$ and $2 / 3$ of surface \\
\hline 5 & Plaque covering $2 / 3$ or more of surface \\
\hline
\end{tabular}

\section{RESULTS}

34 patients were randomly assigned to the text message or control group. There were 21 females and 13 males with a mean age of 20.2 years, ranging from 17 to 23 years old. Table 4 shows the descriptive statistics of BI, MGI, and PI for both groups at the three time points. As shown in table 5 there were no differences in scores between the groups at baseline $(P$ $<.5)$. At T1, there were no BI, MGI, or PI differences between the groups. At T2, the text message group had a highly significant lower BI $(P=.000)$, MGI $(P$ $=.000)$, and PI $(P=.000)$ scores. Within the groups, 
BI, MGI, and PI highly improved over time in the text and PI did not change significantly. The changes message group $(P=.000)$. Within the control group, across time points in BI, MGI, and PI are displayed in BI became worse over time $(P=.001)$ while MGI, Figures $1-4$, respectively.

Table 4: Descriptive statistics of BI, MGI, and PI for text message and control groups:

\begin{tabular}{|c|c|c|c|c|}
\hline Time interval & $\begin{array}{c}\text { Text message group } \\
\text { mean }\end{array}$ & Text message group SD & Control group mean & Control group SD \\
\hline & & BI & & .664 \\
\hline T0 & 1.47 & .624 & 1.24 & .514 \\
\hline T1 & 1.29 & .470 & 1.53 & .500 \\
\hline T2 & .29 & .470 & 2.00 & .920 \\
\hline T0 & 3.12 & MGI & 2.71 & .809 \\
\hline T1 & 2.47 & .781 & 2.82 & .702 \\
\hline T2 & .65 & .624 & 3.35 & .849 \\
\hline & & .702 & & .659 \\
\hline T0 & 3.00 & $\boldsymbol{P I}$ & 2.71 & .588 \\
\hline
\end{tabular}

Table 5: Paired samples t test:

\begin{tabular}{|c|c|c|c|c|c|c|c|c|}
\hline \multirow[t]{3}{*}{ Pairs } & \multicolumn{5}{|c|}{ Paired Differences } & \multirow[t]{2}{*}{$t$} & \multirow[t]{2}{*}{$d f$} & \multirow[t]{2}{*}{$\underset{\text { (2-tailed) }}{\text { Sig. }}$} \\
\hline & \multirow[t]{2}{*}{ Mean } & \multirow[t]{2}{*}{$\begin{array}{l}\text { Std. devia- } \\
\quad \text { tion }\end{array}$} & \multirow[t]{2}{*}{$\begin{array}{c}\text { Std. error } \\
\text { mean }\end{array}$} & \multicolumn{2}{|c|}{$\begin{array}{l}95 \% \text { confidence interval of } \\
\text { the difference }\end{array}$} & & & \\
\hline & & & & Lower & Upper & & & \\
\hline BI T0 & .235 & .664 & .161 & -.106 & .577 & 1.461 & 16 & .163 \\
\hline BI T1 & -.235 & .562 & .136 & -.524 & .054 & -1.725 & 16 & .104 \\
\hline BI T2 & -1.706 & .470 & .114 & -1.947 & -1.464 & -14.976 & 16 & $.000 *$ \\
\hline MGI T0 & .412 & 1.004 & .243 & -.104 & .928 & 1.692 & 16 & .110 \\
\hline MGI T1 & -.353 & .786 & .191 & -.757 & -.051 & -1.852 & 16 & .083 \\
\hline MGI T2 & -2.706 & .920 & .223 & -3.179 & -2.233 & -12.133 & 16 & $.000 *$ \\
\hline PI T0 & .294 & 1.047 & .254 & -.244 & .832 & 1.159 & 16 & .264 \\
\hline PI T1 & -.353 & .862 & .209 & -.796 & -.090 & -1.689 & 16 & .111 \\
\hline PI T2 & -2.706 & .470 & .114 & -2.947 & -2.464 & -23.754 & 16 & $.000 *$ \\
\hline
\end{tabular}

\section{DISCUSSION}

This study examined the effect of text message reminder which was sent directly to patients on their oral hygiene compliance. Outcome was assessed using BI, MGI, and PI. We found that text messages reminding patients about their oral hygiene resulted in improved oral hygiene compliance over time. This finding is similar to that reported by Eppright et al., ${ }^{(25)}$ who found that sending text messages to the parents was effective for improving oral hygiene compliance 
in orthodontic patients, and to that of Bowen et al., ${ }^{(28)}$ who found that text messages reminding and encouraging good oral hygiene resulted in a less measurable surface area of plaque over time. The text message group demonstrated a highly significant lower BI, MGI, and PI scores at T2, which was 12 weeks after baseline (T0). According to Lally et al., ${ }^{(29)}$ it takes an average time of 66 days to turn a behavior into an automatic habit. This lag time in habit formation may explain why differences in oral hygiene measures were not seen at T1, which was 4 weeks after baseline.

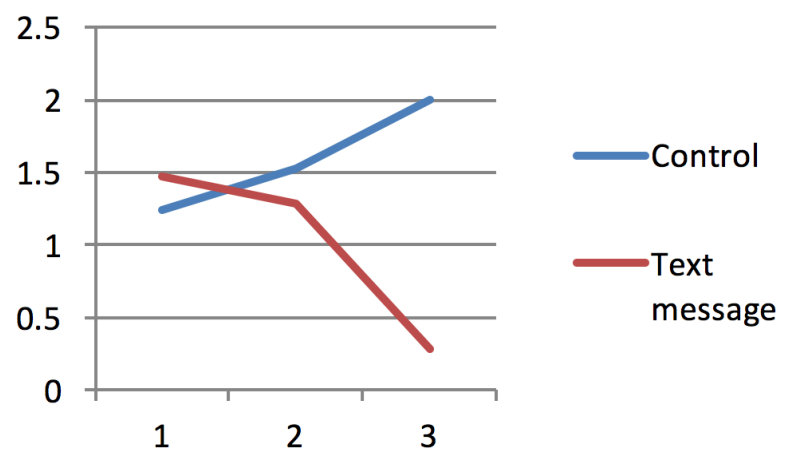

Figure 1: Treatment response for BI over time.

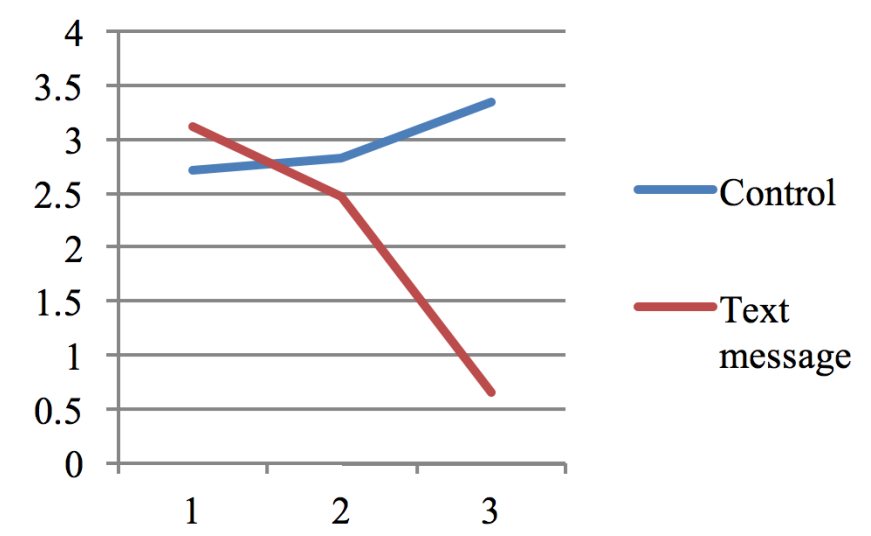

Figure 2: Treatment response for MGI over time.

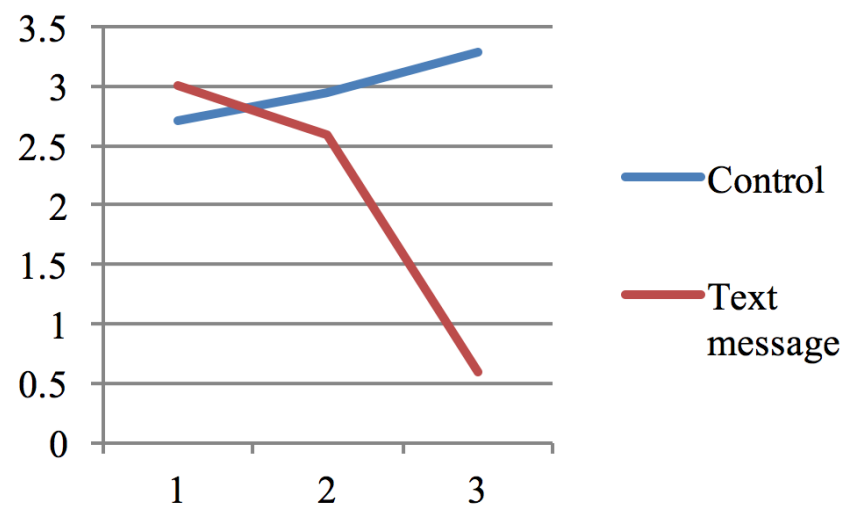

Figure 3: Treatment response for PI over time.

BI is a strong indicator of oral hygiene compliance, as it has been shown to have high sensitivity and specificity in periodontal health evaluation. ${ }^{(30,31)}$ In addition, MGI has demonstrated high sensitivity for assessing resolution and progression of gingivitis. ${ }^{(32)}$ Studies have indicated that MGI and BI correlate well and should produce comparable results when used together in a clinical trial. ${ }^{(32)}$ Therefore, significantly lower BI and MGI scores in the text message group at T2 should be viewed as strong evidence of the effectiveness of the text messaging.

The results of this study suggest that a text message reminder improves oral hygiene compliance, but it is possible that its effectiveness was simply caused by the extra attention provided to the text message group, and the declined in the compliance for the control group may be simply because they were not being given any attention. Since this study looked at only a short time span, the question as to whether there would be any long-lasting effect from text messaging requires further investigation.

The use of text messaging is a very simple way of maintaining a good communication with the patient, especially between long span appointments which show that the orthodontist is still involved and concerned about the patient's well-being. This has been shown to be important in influencing patient satisfaction and promoting orthodontist-patient relationships ${ }^{(33)}$.

In recent years, many orthodontists used e-mail either as a replacement or adjunctive to cellular telephone calls as an appointment reminder for their patients. But thinking of that every cellular telephone has the ability to receive a text message, it is easy to realize that this is reasonably a preferred method to communicate. Furthermore, the number of individuals owning a cell phone is greater than the number of individuals owning a computer ${ }^{(34)}$. Direct text messaging of patients began as a way to remind patients of appointments but may now be used to remind them of brushing, elastic wear, wearing retainers, and so forth. Text message reminder system, as used in this study, is an effective means of improving oral hygiene compliance in orthodontic patients, beside, is a novel way to reach many patients with very little administrative time.

\section{CONCLUSION}

The sending of text messages directly to patients explaining and reminding them of the importance of oral hygiene is an effective way to improve oral hygiene compliance in orthodontic patients over a 3 months period.

\section{REFERENCES}

1. Skidmore K, Brook K, Thomson W, Harding W. Factors influencing treatment time in orthodontic patients. Am J Orthod Dentofacial Orthop. 2006;129:230-238. 
2. Derks A, Kuijpers-Jagtman A, Frencken J, Van't Hof M, Katsarose C. Caries preventive measures used in orthodontic practices: An evidence-based decision? Am J Orthod Dentofacial Orthop. 2007;132:165-170.

3. Bollen A, Cunha-Cruz J, Bakko D, Huang G, Hugoel P. The effects of orthodontic therapy on periodontal health: a systematic review of controlled evidence. J Am Dent Assoc. 2008;139:413-422.

4. Zachrisson S, Zachrisson B. Gingival condition associated with orthodontic treatment. Angle Orthod. 1972;42:26-34.

5. Alstad S, Zachrisson B. Longitudinal study of periodontal condition associated with orthodontic treatment in adolescents. Am J Orthod Dentofacial Orthop. 1979;76:277-286.

6. Zachrisson B, Alnaes L. Periodontal condition in orthodontically treated and untreated individuals, I: loss of attachment, gingival pocket depth and clinical crown height. Angle Orthod. 1973;43:402-411.

7. Burket L. Effects of orthodontic treatment on the soft periodontal tissues. Am J Orthod Dentofacial Orthop. 1963; 49:660-671.

8. Atack N, Sandy J, Addy M. Periodontal and microbiological changes associated with the placement of orthodontic appliances: a review. J Periodontol. 1996;67:78-85.

9. Schluger S. Periodontal aspects of orthodontic treatment. JPO J Pract Orthod. 1968;5:111-117.

10. Al-Jewair T, Suri S. Predictors of adolescent compliance with oral hygiene instructions during two-arch multibracket fixed orthodontic treatment. Angle Orthod. 2011;81: 525531 .

11. Cantekin K, Celikoglu M, Karadas M, Yildirim H, Erdem A. Effects of orthodontic treatment with fixed appliances on oral health status: a comprehensive study. J Dent Sci. 2011;6: 235-238.

12. Lundstrom F, Hamp S, Nyman S. Systematic plaque control in children undergoing long-term orthodontic treatment. Eur J Orthod. 1980;2:27-39.

13. Feliu J. Long-term benefits of orthodontic treatment on oral hygiene. Am J Orthod. 1982;82:473-477.

14. Bratthall D. Programmed self-instruction in oral hygiene. J Periodontol Res. 1967;2:207-214.

15. Casey G. Maintenance of oral hygiene and dental health during orthodontic therapy. Clin Prev Dent. 1988;10:11-13.

16. Boyd R. Enhancing the value of orthodontic treatment: incorporating effective preventive dentistry into treatment. Am J Orthod Dentofacial Orthop. 2007;17:601-603.

17. Fjeldson B, Marshall A, Miller Y. Behavior change interventions delivered by mobile telephone short-message service. Am J Prev Med. 2009;45:184-198.

18. Cole-Lewis H, Kershaw T. Text messaging as a tool for behavior change in disease prevention and management. Epidemiol Rev. 2010;32:56-69.
19. Fjeldsoe B, Marshall A, Miller Y. Behavior change interventions delivered by mobile telephone short-message service. Am J Prev Med. 2009;36:165-173.

20. Almog D, Devires J, Borrelli J, Kopycka-Kedzierawski D. The reduction of broken appointment rates through an automated appointment confirmation system. J Dent Educ. 2003;67:1016-1022.

21. Roth J, Kula T, Claros A, Kula K. Effect of a computergenerated telephone reminder system on appointment attendance. Semin Orthod. 2004;10:190-193.

22. Can S, Marfarlane T, O'Brien K. The use of postal reminders to reduce non-attendance at an orthodontic clinic: a randomized controlled trial. Br Dent J. 2003;195:199-201.

23. Foley J, O'Neill M. Use of mobile telephone short message service (SMS) as a reminder: the effect on patient attendance. Eur Arch Paediatr Dent. 2009;10:15-19.

24. Keith D, Rinchuse D, Kennedy M, Zullo T. Effect of textmessage follow-up on patient's self-reported level of pain and anxiety. Angle Orthod. 2013;83:605-610.

25. Eppright M, Shroff B, Best A, Barcoma E, Lindauer SJ. Influence of active reminders on oral hygiene compliance in orthodontic patients. Angle Orthod. 2014;84:208-213.

26. Saxton CA, van der Ouderaa FJ. The effect of a dentrifice containing zinc citrate and Triclosan on developing gingivitis. J Periodontal Res. 1989;24:75-80.

27. Quigley G, Hein JW. Comparative cleansing efficiency of manual and power brushing. J Am Dent Assoc. 1962;65: 26-29.

28. Bowen B, Rinchuse D, Zello T, DeMaria M. The influence of text messaging on oral hygiene effectiveness. Angle Orthod. 2015;85:543-548.

29. Lally P, Van Jaarsveld C, Potts H, Wardle J. How habits are formed: modelling habit formation in the real world. Eur J So

30. Lang NP, Adler R, Joss A, Nyman S. Absence of bleeding on probing. An indicator of periodontal stability. J Clin Periodontol. 1990;17:714-721.

31. De Souza PH, de Toledo BE, Rapp GE, Zuza EP, Neto $\mathrm{CB}$, Mendes AJ. Reliability of bleeding and non-bleeding on probing to gingival histological features. J Int Acad Periodontol. 2003;5:71-76.

32. Barnett ML. Suitability of gingival indices for use in therapeutic trails. Is bleeding a sine qua non? J Clin Periodontol. 1996;23:582-586.

33. Sinha P, Nanda R, McNeil D. Perceived orthodontist behaviors that predict patient satisfaction, orthodontistpatient relationship, and patient adherence in orthodontic treatment. Am J Orthod Dentofacial Orthop. 1996;110: $\quad 370-377$.

34. Hamilton JY. Orthodontists shd B txN Patients. The Progressive Orthodontist. 2011;Q2:42-44. 